nature

immunology

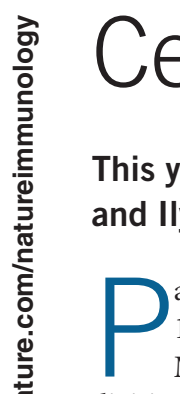

Celebrating great ideas

This year marks the 100th anniversary of the Nobel Prize in Physiology or Medicine awarded jointly to Paul Ehrlich and Ilya Metchnikov. aul Ehrlich and Ilya Metchnikov were awarded the Nobel Prize in 1908. Some have suggested that Ehrlich's work on antibodies and Metchnikov's work on phagocytosis laid the groundwork for the division of all things immunological into 'adaptive' and 'innate' processes. But their Nobel Prize lectures make two things apparent: Ehrlich and Metchnikov had distinct interests and any idea that either man would 'slice up' immunology into innate and adaptive processes is certainly an historical anachronism. For Metchnikov, biomedical questions were to be solved by studying comparative biology. Accordingly, his lecture begins with a discussion of the origin of digestive organs in the animal world and then proceeds to discussions of the "floating larvae of starfish" and infection of the water flea (daphniae) by a microbe that produces spores. Those early studies were central to Metchnikov's later work on phagocytosis and the complex processes involved in killing microbes, one of which was through 'digestion' of the microbe by a phagocyte.

For Ehrlich, the "problem of cell life" was to be answered by looking down an order of magnitude from organisms to "the most subtle chemism of cell life." At the root of this endeavor was chemistry. The bulk of Ehrlich's lecture describes the many types of receptors or 'lateral chains' - for example, those beneficial for the organism were called 'nutriceptors' - that are "discharged from the cell in excess" and circulate as antitoxins (antibodies) with specificity for particular microbial toxins. Ehrlich's ideas, dubbed the 'side-chain' theory, were in part an extension of earlier work by Emil Fischer on the molecular 'lock-and-key' mode of chemical interaction.

In this issue of Nature Immunology, two reports pay homage to the achievements of Ehrlich and Metchnikov, who are often considered by others to be among the earliest true immunologists. Their individual achievements are discussed in an historical commentary by Stefan H.E. Kaufmann, and Carl Nathan presents an overview of the meeting "Metchnikov's Legacy in 2008" that recently took place at the Institut Pasteur. No doubt innate and adaptive aspects of immune responses owe their beginnings to Ehrich and Metchnikov, but their legacy would be more accurately seen as a seminal contribution to establishment of immunology as a distinct field of study.

\title{
Science in an open society
}

\section{A vibrant and eclectic international immunology meeting recently took place in the Arabian Desert of the United Arab Emirates, in the heart of the Islamic world.}

$\mathrm{t}$ $\mathrm{t}$ is by now a truism that science and religion can be anathema to one another, with the familiar refrain that religious ideology and its adherence to strict interpretation of divine texts can usurp the very possibility of scientific progress. It would be pointless to argue that this conjecture has not been true of many societies and cultures throughout world history. But a relatively frequent topic discussed today is the extent to which Islamic countries in particular lag behind the rest of the world in scientific understanding.

Ideology and repression of ideas can take place any time and in diverse societies. Perhaps societies never fully 'immunize' themselves against irrationality and/or the imposition of ideology onto scientific pursuits? In the best of circumstances, however, science is conducted in a way that researchers say it should be done, with the state functioning as a benefactor for and, at times, a regulator of science. Alas, this is not the case today in many countries of the world.

Many commentaries have pointed to Islamic countries as places where religious belief has been particularly hostile to science. Yet some of the 'pinnacles of open society' themselves have been plagued by repression of scientific ideas. In the USA, for example, religious views have considerably influenced discussions of stem cell research, abortion and evolution.
President George Bush's veto of stem cell research legislation, as well as the recent battle in Kansas between those who favor intelligent design and those who favor evolution, exemplify this influence. Evidence that such issues reflect a broad underlying current includes a recent Gallup poll showing that $60 \%$ of Americans believe the earth, created as is by God, is about 10,000 years old. Certainly, ideologically driven hostility to scientific ideas and progress deserves swift and strong criticism wherever it is found, whether in Kansas or in the Islamic world.

In this issue of Nature Immunology, we focus on the fact that scientific ideas do flourish in the Islamic world. Basel al-Ramadi, Adrian Hayday and Wilhelm Schwaeble provide an overview of the Third Al-Ain International Immunology meeting held in the United Arab Emirates 17-20 March 2008. And in an upcoming issue, Basel al-Ramadi and colleagues will discuss the status of scientific funding for immunology research and the prospects for future achievements in key countries of the Middle East.

Although scientific progress may not be moving quickly in all Islamic countries, we hope these two reports will demonstrate the vitality of immunological scientific inquiry in the United Arab Emirates and beyond. Such examples provide hope that scientific inquiry does live in harmony with Islamic religious belief. 